\title{
Liebe Leser und Leserinnen,
}

(ja, Sie lesen die richtige Reihenfolge), hiermit legen wir Ihnen das erste Heft mit Themenschwerpunkt der „körper - tanz bewegung“ (ktb) vor, und es beschäftigt sich mit „dem Mann und dem Körper“.

Warum gerade dieses Thema? Weil die Medizin, die Pädagogik, die Psychotherapie und vor allem die Körper(psycho)therapie in den letzten Jahrzehnten eine weitgehend weibliche Angelegenheit geworden ist und weil auch bisher in der ktb weit mehr weibliche Autorinnen veröffentlicht haben als männliche. Die Lebenswelten von Männern und Frauen differieren jedoch erheblich, nicht immer ist eine Therapeutin in der Lage, ihre männlichen Patienten „richtig“ zu verstehen. Wir wissen z. B., dass 30 Prozent der jungen Männer um die 30 heute eine Identitätskrise durchmachen - weit mehr als die jungen Frauen! Wie kommt das?

Mit Ferdinand Mitterlehner (zusammen mit Claudia Christ), Konrad Heiland, Jochen Kehr und Hans Schmeißer haben wir vier Männer eingeladen, uns ihre Perspektiven zu Männerwelten und tanzenden Männern in der Therapie, zu Stolpersteinen in der Therapie mit Männern und zu männlichen Vorstellungen über Autonomie und ein funktionalistisches Körperverständnis darzulegen. Alle vier sind Männer, die kreative bzw. bewegte Elemente in ihren Therapien integrieren, die aber auch darüber schreiben können, was es heißt, heutzutage ein Mann in seinem Körper zu sein und sich dieses Körpers auch professionell zu bedienen.

Nur ein paar Aspekte, die Sie beim Lesen dieses Heftes vertiefen können, seien vorab

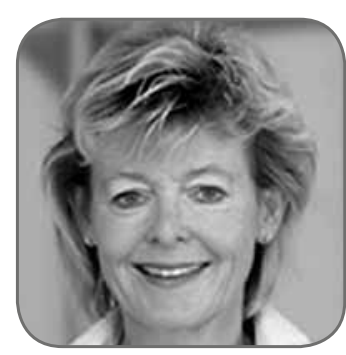

genannt: Männer erleben sich selbst vermehrt als unsichere Jungen, wenn z. B. ihre eigenen Söhne pubertieren, sollen aber gleichzeitig als starke Identifikationspersonen für die ganze Familie fungieren. Sie haben signifikant mehr mit (körperlicher) Gewalt und Suchtthemen zu tun als Frauen und rutschen nicht selten in ein männliches Identitätsdilemma hinein: Starke Erwartungen werden an ihre „mütterliche“ Rolle als Beziehungspartner gestellt bei gleichzeitigem Fokus auf Erfolg, Stabilität und Unabhängigkeit, die sie alle drei bitte ebenfalls bieten sollen. Stand bei Freud der Vater weniger im Fokus und trat erst mit etwa drei Jahren über den Ödipuskomplex in den Vordergrund des therapeutischen Interesses, so sind heutzutage seine grundsätzliche Beziehungs- und Triangulierungsfähigkeit sowie seine Kochund Wickelkünste gefragt.

Dieses Heft beschäftigt sich mit männlicher Körperlichkeit, gesellschaftlicher Teilhabe von Männern, ihrem Risikoverhalten und ihrer Krankheitsverarbeitung - sowohl unter einer wissenschaftlich-kritischen, als auch unter einer praxisnahen Perspektive. Es wird unter anderem auch die Rolle des depressiven Mannes unter der Maske des Autoritär-Kritischen 
angerissen, was immense körperliche Auswirkungen auf zwischenmenschliche Kommunikation und auf das Kontaktverhalten zwischen den Geschlechtern haben kann: Soll männlichen Beziehungsproblemen bzw. männlichen Somatisierungstendenzen oder männlichen Depressionen mit einer „männlich ausgerichteten“ Körper-, Bewegungs- und Tanztherapie begegnet werden?

Um die Gender-Perspektive aber nicht gänzlich zu vernachlässigen - und insofern über unseren ersten Themenschwerpunkt hinaus - finden Sie einen Artikel zu Tanztherapie mit an Krebs erkrankten Frauen und Männern von Elana Mannheim und Maria
Gärtner sowie Tagungsberichte und wie immer Aktuelles aus Medien und Forschung.

Wir würden uns übrigens über Rückmeldungen und Vorschläge freuen, ab und zu oder immer (?) Themenschwerpunkte zu gestalten. Was meinen Sie? Im Namen des gesamten Redaktionsteams wünsche ich Ihnen nun eine anregende Lektüre!

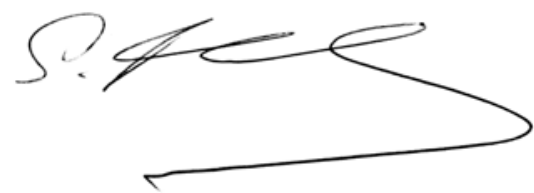

Dr. Sabine Trautmann-Voigt

Mitherausgeberin „körper - tanz - bewegung“ 